\title{
Sex-related differences in the immune response of weanling piglets exposed to low doses of fumonisin extract
}

\author{
Daniela E. Marin ${ }^{1,2}$, Ionelia Taranu ${ }^{1,2}$, Florentina Pascale ${ }^{3}$, Alexandru Lionide ${ }^{2}$, Radu Burlacu ${ }^{4}$, \\ Jean-Denis Bailly ${ }^{5}$ and Isabelle P. Oswald ${ }^{1 *}$ \\ ${ }^{1}$ Laboratoire de Pharmacologie-Toxicologie, UR 66, Institut National de la Recherche Agronomique, Toulouse, France \\ ${ }^{2}$ IBNA, Institute of Biology and Animal Nutrition, Balotesti, Romania \\ ${ }^{3}$ Pasteur Institute, Bucharest, Romania \\ ${ }^{4}$ Institute of the Bovine Research Development, Balotesti, Romania \\ ${ }^{5}$ Ecole Nationale Vétérinaire, Toulouse, France
}

(Received 22 July 2005 - Revised 24 January 2006 - Accepted 3 February 2006)

Fumonisin $\mathrm{B}_{1}\left(\mathrm{FB}_{1}\right)$ is a mycotoxin produced by Fusarium verticillioides, a fungus that commonly contaminates maize. Sex-related effects of $\mathrm{FB}_{1}$ have been observed with respect to carcinogenicity in rodents, to performances in pigs and immunosuppression in mice. In the present study the sex-related effect of $\mathrm{FB}_{1}$ on the pig immune response was determined. Female and castrated male piglets received for $28 \mathrm{~d}$ either control feed or feed contaminated with $8 \mathrm{mg} \mathrm{FB} / \mathrm{kg}$ feed in the form of $F$. verticillioides culture material. At day 7 and day 21 , animals were immunised subcutaneously with a Mycoplasma agalactiae vaccine. Ingestion of $\mathrm{FB}_{1}$-contaminated feed significantly decreased weight gain in males but had no effect in females. No sex-related difference was observed in biochemical parameters, but a higher level of creatinine was noted in toxin-treated animals. $\mathrm{FB}_{1}$ also altered the pig immune response in a sex-specific manner. In males, ingestion of $\mathrm{FB}_{1}$-contaminated feed significantly decreased specific antibody levels after vaccination as well as the mRNA expression level of IL-10. In females, the toxin has no effect on specific antibodies or on cytokine mRNA levels. The results of the present study indicate that $\mathrm{FB}_{1}$ is immunosuppressive in pigs. The magnitude of this $\mathrm{FB}_{1}$-induced immunosuppression is highly dependent on sex, with males being more susceptible than females.

Fumonisin: Mycotoxins: Immunosuppression: Food contamination: Pig: Gender-related effects

Mycotoxins are secondary metabolites of fungi, which may contaminate animal feeds and human foodstuffs. The global occurrence of mycotoxins is considered an important risk factor for human and animal health, as up to $25 \%$ of the world crop production may be contaminated (Fink-Gremmels, 1999; Bouhet \& Oswald, 2005; Oswald et al. 2005).

Fumonisin $\mathrm{B}_{1}\left(\mathrm{FB}_{1}\right)$ belongs to the fumonisin family of toxins which are produced by Fusarium verticillioides and $F$. proliferatum fungi that commonly contaminate maize. Recent surveys of fumonisin contamination of food and feed in Europe and the USA also have raised concerns about the extent of $\mathrm{FB}_{1}$ contamination of maize and its implications for food safety (Murphy et al. 1996; International Programme on Chemical Safety, 2000). $\mathrm{FB}_{1}$ was found in up to $50 \%$ of maize samples collected between 1988 and 1991 from the mid-Western USA (Murphy et al. 1993). In this survey, up to $10 \%$ of the samples had toxin levels between 10 and 50 parts per million (Murphy et al. 1993). Similarly, another survey of fumonisins in maize gluten and other maize products in the UK found these mycotoxins in almost every sample at concentrations of up to 32 parts per million (Scudamore et al. 1990).
The mechanisms of $\mathrm{FB}_{1}$ toxicity are complex and may involve several molecular sites (Riley et al. 1998). The primary biochemical effect of fumonisins is the inhibition of ceramide synthase leading to the accumulation of sphingoid bases and sphingoid base metabolites, and the depletion of more complex sphingolipids (Riley et al. 1998; Merrill et al. 2001).

Ingestion of high doses of $\mathrm{FB}_{1}$ induces different speciesspecific effects in domestic and laboratory animals including pulmonary oedema and cardiovascular changes in the pig, leukoencephalomalacia in horses and nephrotoxicity in rats, rabbits and lambs. It also causes hepatotoxicity in all species studied (Bolger et al. 2001; Haschek et al. 2001). This toxin has also been reported to be a contributing factor in human oesophageal cancers (International Agency for Research on Cancer, 2002). Ingestion of low doses of $\mathrm{FB}_{1}$ increases intestinal and pulmonary infection in piglets (Oswald et al. 2003; Halloy et al. 2005) and alters immune responses in pigs and in mice (Bhandari et al. 2002; He et al. 2002; Bouhet et al. 2004; Taranu et al. 2005).

Fumonisin toxicity has not only been demonstrated to be species- and tissue-specific, but has also been shown to be sex-specific (Rotter et al. 1996; Bhandari et al. 2001; 
Howard et al. 2001; Johnson \& Sharma, 2001). In a 2-year feeding study, hepatocellular adenomas and carcinomas were induced by $\mathrm{FB}_{1}$ in female mice but not in males. In the same study it was also revealed that male Fischer F344 rats developed renal tumours that were not seen in females (Howard et al. 2001). Sex-specific effects of $\mathrm{FB}_{1}$ have been described in the immune response of mice following subcutaneous injection (Bhandari et al. 2001; Johnson \& Sharma, 2001). In females, $F_{1}$ treatment reduced relative spleen and thymus weights, splenic cellularity, thymocyte CD $4+$ / $\mathrm{CD} 8+$ double positive cells, lymphocyte proliferation, and IL-2 expression. These effects were not observed in male mice (Johnson \& Sharma, 2001). In addition, FB $_{1}$ administration caused increased expression of TNF- $\alpha$, IL-12p40, interferon (IFN)- $\gamma$, IL-1 $\beta$, IL-6 and IL-10 in male liver while female mice only showed an increased expression of IL-6 and a down modulation of IFN- $\gamma$ (Bhandari et al. 2001). In pigs, males are more adversely affected by low doses of purified $\mathrm{FB}_{1}$ than females, as indicated by the effect of the toxin on average daily gain, serum biochemical parameters, pancreas and adrenal weight (Rotter et al. 1996).

In the present study the sex-specific effects of $\mathrm{FB}_{1}$ on the pig immune response was investigated. Ingestion of mycotoxin-contaminated feed altered the immune response of males but did not affect the immune response of females as indicated by the expression of T-helper (Th) 2 cytokines and by the production of specific antibodies upon vaccination.

\section{Materials and methods}

\section{Experimental design}

Twenty, 4-week-old, crossbred weanling piglets (ten females and ten castrated males) were studied for $28 \mathrm{~d}$. The animals were from seven different litters and were balanced for litters across treatments. They were acclimatised for at least 1 week before being used in the experimental protocol and were given ad libitum access to water and feed. They were fed a maize-soyabean-meal-based diet (Marin et al. 2002) supplemented with or without a fumonisin-containing fungal extract. The extraction procedure following in vitro culture of the $F$. verticilloides strain NRRL 34281 has been described (Oswald et al. 2003). Briefly, sterilised maize inoculated with the fungal strain was incubated for 4 weeks at $25^{\circ} \mathrm{C}$. The culture was extracted with acetonitrile-water, filtered, and concentrated. The crude extract contained $54 \% \mathrm{FB}_{1}, 8 \% \mathrm{FB}_{2}$ and $9 \% \mathrm{FB}_{3}$ (Tran et al. 2003). We verified that it did not contain detectable amounts of zearalenone, deoxynivalenol, fusarochromanone or trichothecenes (Oswald et al. 2003). The extract was incorporated into the pig basal diet to provide $8 \mathrm{mg} \mathrm{FB} / 1 / \mathrm{kg}$ feed. Considering the average feed consumption of the animals, this corresponded to doses of 0.99 and $1.49 \mathrm{mg} / \mathrm{kg}$ body weight per $\mathrm{d}$ for the first and the second halves of the experiment. Body weights and food consumption were recorded weekly throughout the experiment. Animals were cared for in accordance with the National Institute of Health Guide.

\section{Immunisation and blood sample collection}

On day 7 and day 21 of the experiment, all piglets were immunised by subcutaneous inoculation with a $1 \mathrm{ml}$ suspension of
Agavac ${ }^{\circledR}$ (Institute Pasteur, Bucharest, Romania) as previously described (Marin et al. 2002). This vaccine consists of a combination of formol-inactivated Mycoplasma agalactiae strains re-suspended in aluminium hydroxide. On day 0 , day 20 and day 28 of the experiment, blood samples were aseptically collected by jugular vein puncture. Syringes without anticoagulant were used to collect serum for antibody and biochemical parameter measurements and syringes containing lithium-heparin were used to collect blood for measuring cytokine mRNA expression.

\section{Measurement of blood biochemical parameters}

Serum concentrations of $\mathrm{Na}, \mathrm{K}$, chloride, $\mathrm{Ca}, \mathrm{P}$, total proteins, urea, creatinine, glucose, cholesterol, triacylglycerols and bilirubin, and concentrations of alkaline phosphatase, glutamate pyruvate transaminase, glutamate oxaloacetate transaminase, $\gamma$-glutamyl transferase and lactate dehydrogenase were determined on a Vitros 950 IRC analyser (Ortho Clinical Diagnostics, Raritan, NJ, USA) at the Laboratory of Biochemistry (Rangueil Hospital, Toulouse, France).

\section{Measurement of total and specific antibody levels}

Total concentrations of the different Ig subsets (IgG, IgA and IgM) were measured by ELISA (Bethyl, Interchim, Montlucon, France) as previously described (Taranu et al. 2005).

Antibodies against $M$. agalactiae were also measured by ELISA. Briefly, ELISA plates were coated with supernatant fraction from ultrasonicated $M$. agalactiae culture. Diluted serum samples (1/100) were then added to the plates and the anti-mycobacterial antibodies were detected with peroxidaselabelled anti-pig IgG (Marin et al. 2002). The absorbance at $405 \mathrm{~nm}$ was recorded using an ELISA plate reader.

\section{Blood cell culture for cytokine mRNA expression analysis}

The mRNA expression of five different cytokines was analysed in the blood samples obtained from the control and $\mathrm{FB}_{1}$-treated animals. Whole blood was cultured as previously described (Marin et al. 2002). Briefly, blood was diluted 10fold in RPMI 1640 supplemented with $2 \mathrm{mM}$-L-glutamine, penicillin $(100 \mathrm{U} / \mathrm{ml})$, streptomycin $(0.1 \mathrm{mg} / \mathrm{ml}$; Sigma, St Louis, MO, USA), $10 \%$ fetal calf serum (Hyclone, Perbio, Brebieres, France) and then $2 \mathrm{ml}$ of diluted blood was stimulated with phytohaemagglutinin $(10 \mu \mathrm{g} / \mathrm{ml})$. After $24 \mathrm{~h}$ of culture, cell pellets were harvested and re-suspended in $1 \mathrm{ml}$ Trizol (Gibco BRL Life Technologies, Cergy Pontoise, France) then frozen at $-80^{\circ} \mathrm{C}$ until used.

\section{Determination of cytokine $m R N A$ expression by semi- quantitative reverse transcriptase polymerase chain reaction}

Total RNA was extracted following the manufacturer's recommendations and quantified by spectrophotometry. Semiquantitative determination of IL-4, IL-10, IL-6, IL-2 and IFN- $\gamma$ and cyclophilin, chosen as a housekeeping gene, was carried out using RT-PCR performed as previously described (Dozois et al. 1997; Fournout et al. 2000). Briefly, mRNA was reverse transcribed with Moloney leukaemia virus RT (Promega, Charbonnières, France) and amplified with DNA 
Taq polymerase enzyme (Invitrogen, Life Technology, Cergy Pontoise, France) using the already published primer sequences (Dozois et al. 1997; Fournout et al. 2000). Semiquantitative analysis of PCR products was done by hybridisation of ${ }^{33} \mathrm{P}$-labelled specific oligonucleotide probes to PCR products immobilised on nitrocellulose membranes by dot blotting (Pié et al. 2004). The DNA probes used for hybridisation of the different cytokines have already been described (Darwich et al. 2003; Pié et al. 2004). The relative amounts of each product were determined by measuring radioactivity with a Phosphor Imager (Molecular Dynamics, Sunnyvale, CA, USA). For each cytokine, the amounts of RT-PCR products were normalised to the values obtained with cyclophilin, which was used as an internal standard for each sample.

\section{Statistical analysis}

All data are expressed as mean values and standard errors of the mean. Statistical differences between groups for feed consumption, biochemical parameters, serum immunoglobulin subsets and cytokine expression levels were determined using an ANOVA two-way analysis; the measurements for these parameters were done once at the end of the experiment. A two-way ANOVA with replications was used to analyse the antibody and the average weight gain during the experiment. Further differences between means were determined by the least square difference Fisher procedure. Values of $P<0.05$ were considered significant.

\section{Results}

\section{Sex-related effect of fumonisin on animal performance}

We first investigated the sex-related effect of $\mathrm{FB}_{1}$ treatment on clinical signs and animal weight. The feeding of $8 \mathrm{mg} \mathrm{FB} / \mathrm{kg}$ feed for $28 \mathrm{~d}$ did not produce any detectable alteration in the general status of either male or female piglets. As shown in Fig. 1, in females the feeding of fumonisin had no significant effect on the average daily weight gain $(P=0.821)$. By contrast, in males, throughout the 4 weeks of the experiment, ingestion of fumonisin-contaminated feed decreased $(P=0.001)$ the average daily weight gain by up to $23 \%$ when compared with control. Further differences between control and fumonisin male groups at specific time points were determined by the least square difference Fisher procedure. A significantly treatment effect began after the 3 rd $(P=0.021)$ and the 4th $(P=0.049)$ week of intoxication. This lower weight gain was not due to reduced feed intake. The experimental protocol did not allow measurement of individual feed ingestion but group data indicated that feed consumption was 2.6 and $10.6 \%$ higher for males compared with females during the first and the second halves of the experiment respectively.

\section{Sex-related effect of fumonisin on biochemical parameters}

At the end of the experiment, blood samples were collected from the piglets to investigate the sex-related effect of fumonisin on biochemical parameters. The presence of $\mathrm{FB}_{1}$ in the diet did not alter the activities of serum enzymes including alkaline phosphatase, glutamate pyruvate transaminase,

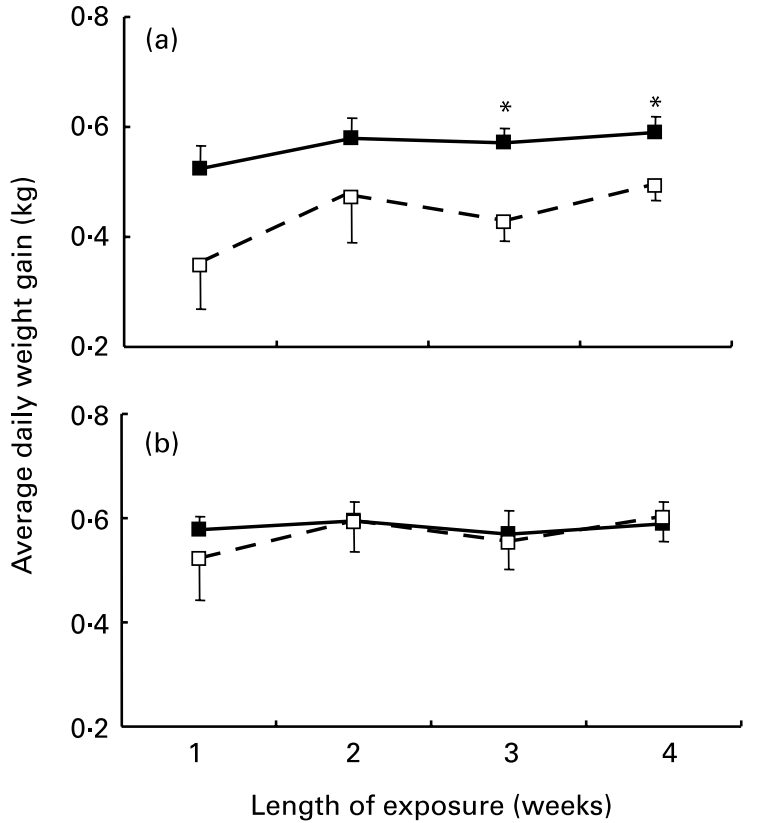

Fig. 1. Sex-related effect of fumonisin on animal daily weight gain. Male (a) or female (b) piglets received a control diet (- - ) or a fumonisin $\mathrm{B}_{1}$-contaminated diet $(-\square-)$. Animals were weighed weekly and results are expressed as the average daily weight gain; values are means for five animals, with the vertical bars representing standard errors. Comparison of the daily weight gain observed in the control and fumonisin $B_{1}$-treated animals was done using a repeated-measures ANOVA $(P=0.82$ for females and $P=0.001$ for males). *At specific time points, mean value was signinficantly different between control and treated groups $(P<0.005$; determined by the least square difference Fisher procedure).

glutamate oxaloacetate transaminase, $\gamma$-glutamyl transferase and lactate dehydrogenase (Table 1). The contamination of pig feed with fumonisin also did not have any influence on the serum concentration of $\mathrm{Na}, \mathrm{K}$, chloride, bicarbonate, $\mathrm{Ca}$, $\mathrm{P}$, protein, urea, glucose, bilirubin, cholesterol and triacylglycerol. By contrast, the feeding of fumonisin-contaminated diet significantly increased the creatinine concentrations in the serum of treated animals $(P=0 \cdot 035)$.

\section{Sex-related effects of fumonisin on total and specific antibody} responses

To investigate the sex-related effect of fumonisin on the immune responses, piglets were immunised with Mycoplasma. Serum antibody levels were measured by ELISA after the primary (day 21) and the secondary injections (day 28). As expected, the vaccinal injections increased the antibody levels (Fig. 2). This increase was observed in both males and females receiving either the control or the fumonisin-contaminated diet. Nevertheless a sex-related effect of fumonisin was observed on mycoplasma-specific antibody levels. Repeated-measures ANOVA used for data statistical analysis showed that both ingestion of fumonisin-contaminated feed and the time of exposure significantly decreased the specific antibody synthesis $(P=0.022)$ in males. The further pairwise comparison between the control and $\mathrm{FB}_{1}$ group at each specific time point resulted in a $38 \%$ decrease in specific antibody levels $(P=0.045)$ at day 28 of the experiment whereas in females, ingestion of the contaminated feed did not have any 
Table 1. Effect of dietary fumonisin administration on blood biochemical parameters in piglets† (Mean values with their standard errors)

\begin{tabular}{|c|c|c|c|c|c|c|c|c|}
\hline \multirow[b]{3}{*}{ Biochemical parameters } & \multicolumn{4}{|c|}{ Males } & \multicolumn{4}{|c|}{ Females } \\
\hline & \multicolumn{2}{|c|}{ Control feed } & \multicolumn{2}{|c|}{$\begin{array}{l}\text { Fumonisin- } \\
\text { containing feed }\end{array}$} & \multicolumn{2}{|c|}{ Control feed } & \multicolumn{2}{|c|}{$\begin{array}{l}\text { Fumonisin- } \\
\text { containing feed }\end{array}$} \\
\hline & Mean & SEM & Mean & SEM & Mean & SEM & Mean & SEM \\
\hline $\mathrm{Na}(\mathrm{mm})$ & $141 \cdot 0$ & 1.0 & $145 \cdot 2$ & 0.7 & $141 \cdot 8$ & $1 \cdot 3$ & $146 \cdot 5$ & 3.0 \\
\hline $\mathrm{K}(\mathrm{mm})$ & 8.43 & 0.55 & 7.83 & $0 \cdot 20$ & 6.68 & 0.32 & 8.04 & 0.54 \\
\hline Chloride (mм) & $99 \cdot 8$ & $1 \cdot 2$ & $100 \cdot 2$ & $1 \cdot 3$ & $97 \cdot 6$ & 0.6 & $100 \cdot 2$ & $2 \cdot 7$ \\
\hline Bicarbonate (mM) & $16 \cdot 2$ & 1.6 & $17 \cdot 7$ & 1.0 & $18 \cdot 8$ & $1 \cdot 3$ & $18 \cdot 4$ & 1.5 \\
\hline $\mathrm{Ca}(\mathrm{mm})$ & $2 \cdot 53$ & 0.03 & $2 \cdot 53$ & 0.09 & 2.52 & 0.07 & $2 \cdot 40$ & 0.06 \\
\hline$P(\mathrm{~mm})$ & $4 \cdot 24$ & 0.51 & 4.44 & 0.19 & 4.03 & 0.23 & 4.96 & 0.82 \\
\hline Total protein (g/l) & $69 \cdot 3$ & 1.4 & 73.7 & 3.9 & $65 \cdot 2$ & 1.5 & $66 \cdot 6$ & 1.4 \\
\hline Urea (mm) & $5 \cdot 21$ & $0 \cdot 70$ & 4.46 & 0.73 & $4 \cdot 13$ & 0.48 & $4 \cdot 46$ & 0.71 \\
\hline Creatinine $(\mu \mathrm{M})$ & $85 \cdot 2$ & $4 \cdot 2$ & $97 \cdot 7^{*}$ & $4 \cdot 8$ & $86 \cdot 0$ & 3.6 & $93 \cdot 6^{*}$ & $3 \cdot 3$ \\
\hline Glucose (mM) & 4.26 & 0.51 & 4.05 & 0.36 & 3.89 & 0.25 & 4.05 & $0 \cdot 17$ \\
\hline Bilirubin $(\mu \mathrm{M})^{\prime}$ & $2 \cdot 9$ & 0.3 & $3 \cdot 3$ & 0.3 & $2 \cdot 8$ & 0.4 & $3 \cdot 6$ & 0.9 \\
\hline Cholesterol (mм) & $2 \cdot 77$ & $0 \cdot 19$ & 3.11 & 0.14 & $2 \cdot 81$ & $0 \cdot 24$ & $2 \cdot 90$ & 0.23 \\
\hline Triacylglycerols (mm) & 0.50 & 0.12 & 0.40 & 0.01 & 0.40 & 0.03 & 0.32 & 0.03 \\
\hline Alkaline phosphatase (IU/I) & $205 \cdot 2$ & $28 \cdot 7$ & $283 \cdot 0$ & $88 \cdot 3$ & $198 \cdot 0$ & 39.9 & $266 \cdot 4$ & $61 \cdot 8$ \\
\hline$\gamma$-Glutamyl transferase (IU/I) & $180 \cdot 8$ & 20.9 & $140 \cdot 2$ & $5 \cdot 1$ & $135 \cdot 2$ & $23 \cdot 8$ & 144.4 & 30.5 \\
\hline Aspartate aminotransferase (IU/I) & $76 \cdot 5$ & $1 \cdot 0$ & $60 \cdot 5$ & $3 \cdot 6$ & $52 \cdot 0$ & $8 \cdot 2$ & $60 \cdot 6$ & $2 \cdot 2$ \\
\hline Alanine aminotransferase (IU/I) & $48 \cdot 4$ & $9 \cdot 8$ & $49 \cdot 0$ & $8 \cdot 3$ & $52 \cdot 0$ & 8.2 & $46 \cdot 8$ & $7 \cdot 0$ \\
\hline Lactate dehydrogenase (IU/I) & 1677 & 198 & 1363 & 164 & 1535 & 80 & 1483 & 103 \\
\hline
\end{tabular}

* Mean value was significantly different from that of the animals of the same sex fed the control feed $(P<0.05)$.

$\dagger$ At the end of the experiment, serum from the piglets (four or five per group) was used to measure the blood biochemical parameters.

significant effect $(P=0 \cdot 186)$. This sex-related effect was only observed for specific antibody level and no effect of $\mathrm{FB}_{1}$ was observed on total Ig levels, irrespective of the subsets considered (Table 2).

\section{Sex-related effect of fumonisin on cytokine mRNA expression}

The ability of fumonisin to modulate the cytokine expression in a sex-dependent manner was then investigated on wholeblood samples stimulated with mitogen. The mRNA expression of both Th1 (IL-2, IFN- $\gamma$ ) and Th2 (IL-4, IL-10 and IL-6) cytokines was measured by RT-PCR at the end of the experiment. The mRNA synthesis of Th1 cytokines (IL-2 and IFN- $\gamma$ ) was not modified by the contamination with fumonisin in either male or female piglets (Fig. 3). Ingestion of fumonisin-contaminated feed induced a sex-dependent decrease in the expression of Th2 cytokines. In males, fumonisin treatment decreased the expression level of mRNA encoding for IL-4, IL-6 and IL-10 (by 31, 51 and $45 \%$ respectively). However, the difference was only significant for IL-10 $(P=0 \cdot 040, P=0 \cdot 268, P=0.159$ for IL-10, IL-6 and IL-4 respectively), due to the small number of animals in each group. By contrast, in female piglets, fumonisin treatment did not induce any changes in Th2 cytokine expression.

\section{Discussion}

We have studied the sex-related effects of a sub-chronic exposure (28d) to fumonisin on body-weight gain, blood biochemical parameters and immune response of piglets. In general, males were more adversely affected by the presence of fumonisin in the diet than females. Average daily gain decreased by $23 \%$ in males upon fumonisin treatment, for example, whereas it was not affected in females. Similar results were obtained by Rotter et al. (1996) who demonstrated that castrated pigs were more sensitive to $1-10 \mathrm{mg}$ purified $\mathrm{FB}_{1}$ in the diet than females. Zomborszky et al. (2000), in contrast, did not observe any significant effect on body-weight gain or feed consumption when feeding weanling piglets with $10-40 \mathrm{mg} \mathrm{FB} / 1 \mathrm{~kg}$ feed for 4 weeks.

The present results indicate that low doses of $\mathrm{FB}_{1}$ had limited effects on the blood biochemical parameters of the piglets (Table 1). In a previous study with purified toxin, biochemical changes were only observed at early ( 2 weeks) or late ( 8 weeks) time points (Rotter et al. 1996). No significant effect of $\mathrm{FB}_{1}$ from fungal culture material was observed on blood parameters (Zomborszky-Kovacs et al. 2002).

Sex differences after chronic exposure to $\mathrm{FB}_{1}$ toxicity have been reported for carcinogenic effects in rodents, performance changes in pigs and immunosuppression in mice (Rotter et al. 1996; Bhandari et al. 2001; Howard et al. 2001; Johnson \& Sharma, 2001).

In the present study, sex differences in the immune response of pigs after exposure to fumonisin were observed for both antibody and cytokine responses. The feeding of fumonisin was shown to decrease the specific antibody response developed after immunisation with an anti-Mycoplasma vaccine. This effect was only observed in males and was specific for the acquired immune responses. Immunosuppressive effects of $\mathrm{FB}_{1}$ on humoral immune response have been described after immunisation with sheep erythrocytes in male rats receiving $25 \mathrm{mg} \mathrm{FB} / \mathrm{kg}$ body weight per d (decreased specific IgM; Tryphonas et al. 1997) and in male mice receiving 0.25$5 \mathrm{mg} \mathrm{FB}_{1} / \mathrm{kg}$ body weight in one dose (reduced number of specific plaque-forming cells; Martinova \& Merrill, 1995). Turkeys treated with $200 \mathrm{mg} \mathrm{FB}_{1}$ for 4 weeks also had significantly lower antibody responses during vaccination against Newcastle disease virus ( $\mathrm{Li}$ et al. 2000). 


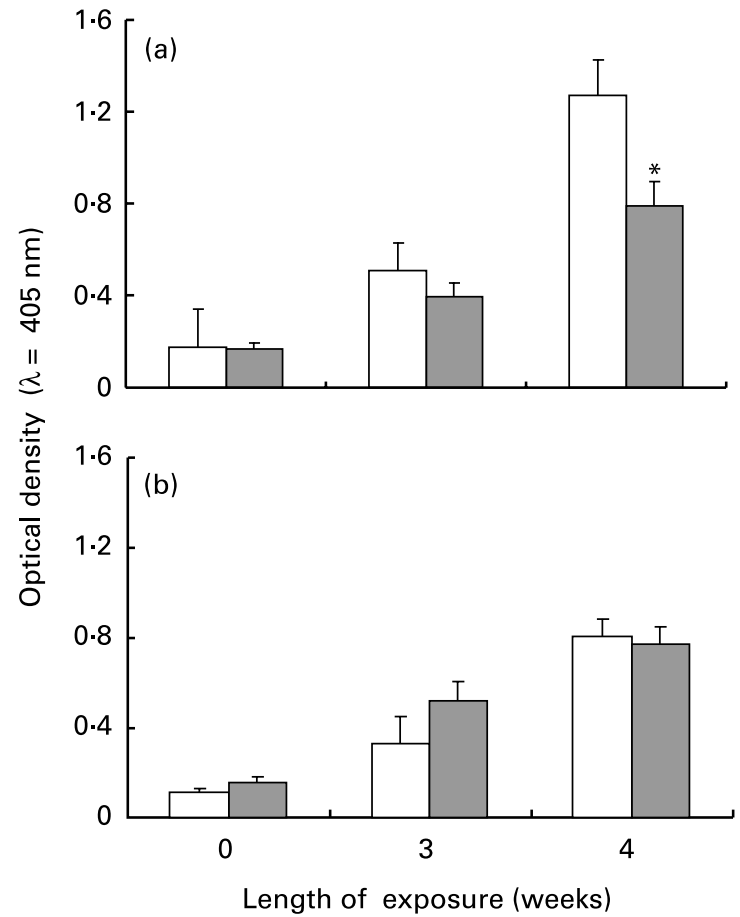

Fig. 2. Sex-related effect of fumonisin on specific antibody production. Male (a) or female (b) piglets received a control diet $(\square)$ or a fumonisin $B_{1}$-contaminated diet $(\square)$. They were immunised with a Mycoplasma vaccine on day 7 and day 21 of the experiment. Serum samples were collected on day 0 , day 21 and day 28 and levels of vaccine-specific antibody were determined by ELISA. Results are expressed as optical density $(405 \mathrm{~nm})$; values are means for five animals, with the vertical bars representing standard errors. Comparison of the specific antibody production in the control and fumonisin $\mathrm{B}_{1}$-treated animals was done using a repeated-measures ANOVA $(P=0.022$ for males and $P=0.18$ for females). ${ }^{*}$ Mean value was significantly different from that of the animals fed the control feed at the same time point $(P<0.05$; determined by the least square difference Fisher procedure).

By contrast, ingestion of a high dose of fumonisin-contaminated feed for $8 \mathrm{~d}$, or a low dose of toxin for 3-4 months, did not alter antibody titres against Aujeszky virus (Tornyos et al. 2003).

In the present study the total level of $\operatorname{Ig}(\operatorname{IgM}, \operatorname{IgG}$ or $\operatorname{IgA}$ ) was not affected by the fumonisin treatment (Table 2). The animals received feed contaminated with $8 \mathrm{mg} \mathrm{FB} / \mathrm{kg}$, and considering their body weight and their feed consumption, this represented an exposure of $1.24 \mathrm{mg} \mathrm{FB}_{1} / \mathrm{kg}$ body weight per $\mathrm{d}$. It seems that higher concentrations of $\mathrm{FB}_{1}$ are necessary to affect the total antibody synthesis. In male SpragueDawley rats, $7.5 \mathrm{mg} \mathrm{FB} / 1 / \mathrm{kg}$ body weight injected intraperitoneally for 4 consecutive days increased serum concentrations of IgM and IgG (Bondy et al. 1995). Similarly, white Leghorn Cornell chicks receiving feed containing $F$. proliferatum culture material with $61 \mathrm{mg} \mathrm{FB} / \mathrm{kg}$ showed a significant suppression in total Ig and IgG levels (Qureshi et al. 1995).

Few investigations have examined the sex-related effect of $\mathrm{FB}_{1}$ on cytokine synthesis (Bhandari et al. 2001; Johnson \& Sharma, 2001), with no studies on pigs. In male mice, $\mathrm{FB}_{1}$ treatment increased the expression of TNF- $\alpha$, IL-12 p40, IFN- $\gamma$, IL-1 $\beta$, IL-6 and IL-10, while female mice showed only an increased expression of IL-6, and a down modulation of IFN- $\gamma$ and IL-2 (Bhandari et al. 2001; Johnson \& Sharma, 2001). In the present study, no effect of fumonisin was observed on Th1 cytokines (IL-2 and IFN- $\gamma$ ). The presence of fumonisin in the diet, however, significantly decreased the mRNA expression level of IL-10, a Th2 cytokine, in male peripheral blood cells. A tendency for a decrease of other Th2 cytokines, IL-6 $(P=0.68)$ and IL-4 $(P=0 \cdot 159)$, were also observed in males. The lack of significance of these parameters may be due to the small number of animals present in each group ( $n$ 5).

Th2 cytokines, especially IL-4, IL- 6 and IL-10, are implicated in the development of the humoral immune response and antibody production (Abbas et al. 1996). IL-4 is involved in the stimulation of the antibody production by B cells, promotion of growth and survival of T cells (Nelms et al. 1998). It is a major factor for the differentiation of B lymphocytes that promotes the Ig switch and favours synthesis of $\mathrm{IgG}$. Moreover, IL- 4 and IFN- $\gamma$ play a key role in the regulation of immune response by their mutually antagonistic mechanisms on cytokine synthesis (Abbas et al. 1996). The development of antibody response is also sustained by IL- 6 , which in addition to its role as activator of the $\mathrm{T}$ cells is involved in the final differentiation of the $\mathrm{B}$ cells in plasmocyte cells which regulate antibody synthesis (Diehl \& Rincon, 2002). IL-10 performs a complex role in the immune response. In cooperation with IL-4, IL-10 stimulates B cells by increasing the expression of class two molecules of the major histocompatibility complex (Abbas et al. 1996) and by stimulating their proliferation and their differentiation to express and produce IgM, IgG and IgA. IL-10 also plays an important role in the cytokine network, by inhibiting cytokine production by Th1

Table 2. Effect of dietary fumonisin administration on serum immunoglobulin $\mathrm{G}$, immunoglobulin $\mathrm{A}$ and immunoglobulin $\mathrm{M}$ in piglets at the end of the experiment*

(Mean values with their standard errors)

\begin{tabular}{|c|c|c|c|c|c|c|c|c|}
\hline & \multicolumn{4}{|c|}{ Males } & \multicolumn{4}{|c|}{ Females } \\
\hline & \multicolumn{2}{|c|}{ Control } & \multicolumn{2}{|c|}{ Fumonisin } & \multicolumn{2}{|c|}{ Control } & \multicolumn{2}{|c|}{ Fumonisin } \\
\hline & Mean & SEM & Mean & SEM & Mean & SEM & Mean & SEM \\
\hline $\lg G(\mathrm{mg} / \mathrm{ml})$ & $21 \cdot 1$ & $4 \cdot 39$ & 17.5 & 2.02 & $20 \cdot 2$ & $1 \cdot 22$ & $21 \cdot 2$ & 1.36 \\
\hline $\lg A(\mathrm{mg} / \mathrm{ml})$ & 2.45 & 0.37 & 1.00 & 0.30 & 1.56 & 0.17 & 1.63 & 0.37 \\
\hline $\operatorname{lgM}(\mathrm{mg} / \mathrm{ml})$ & 3.49 & 0.46 & 3.62 & 0.43 & $3 \cdot 38$ & 0.56 & 3.60 & 0.54 \\
\hline
\end{tabular}

* Piglets (five per group), fed a contaminated or control diet, were bled at the end of the experiment. IgG, IgA and IgM concentrations were determined by ELISA. Two-way ANOVA (animal sex and $\mathrm{FB}_{1}$ treatment) did not reveal any effect of either factor on any serum Ig subset ( $\lg G, \operatorname{Ig} A$ or $\lg M)$. 
(a)

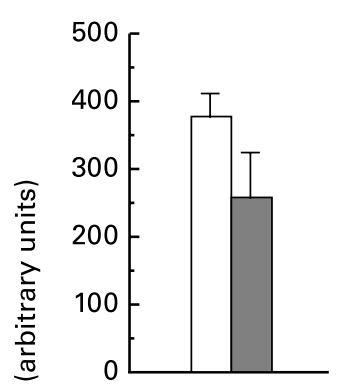

(f)

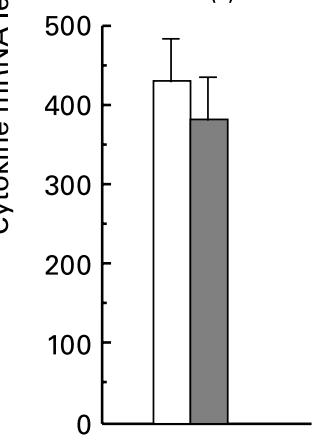

(b)

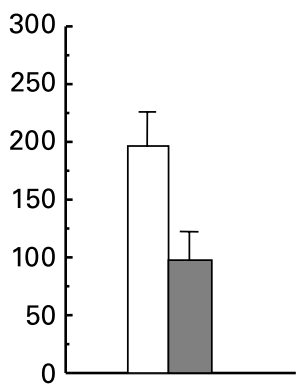

(g)

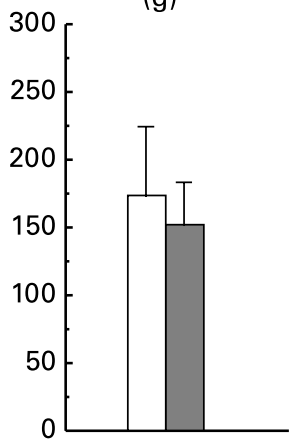

(c)

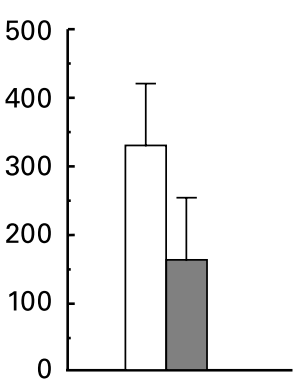

(h)

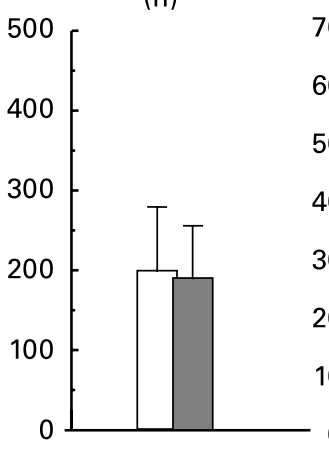

(d)

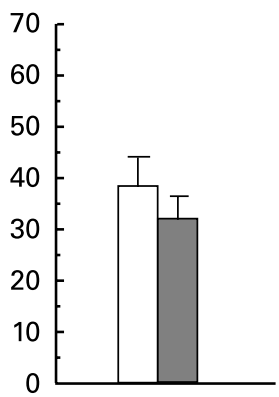

(i)

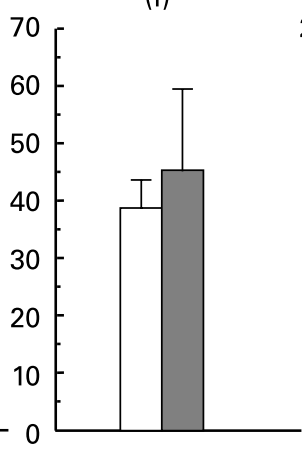

(e)

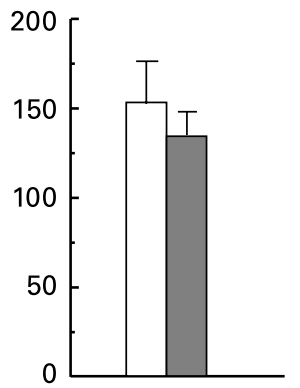

(j)

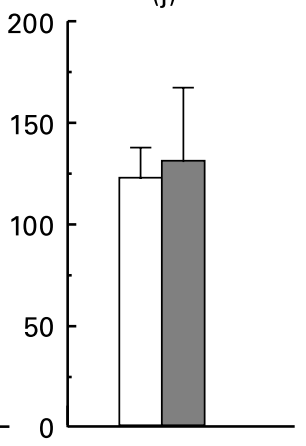

Fig. 3. Sex-related effect of fumonisin on T-helper (Th) 1 and Th2 cytokine mRNA expression. Male (a, b, c, d, e) or female (f, g, h, i, j) piglets were fed a control diet $(\square)$ or a fumonisin $B_{1}$-contaminated diet $(\square)$. Blood samples were taken on day 28 of treatment and cultured for $24 \mathrm{~h}$ with phytohaemagglutinin (10 $\left.\mu \mathrm{g} / \mathrm{ml}\right)$. Total RNA was isolated and assayed for expression of Th1 cytokines (IL-2 (e and j); interferon- $\gamma$ (d and i)) and Th2-type cytokines (IL-4 (a and f); IL-6 (c and h); IL-10 (b and g)). Results are expressed in arbitrary units as the ratio between the cytokine-specific and the cyclophilin RT-PCR values. Values are means for three to five animals, with the vertical bars representing standard errors. ${ }^{*}$ Mean value was significantly different from that of the animals fed the control feed $(P<0.05)$.

lymphocytes and monocytes and macrophages (Mocellin et al. 2003). In the present study, the decreased expression of Th2 cytokines (IL-10, IL-4 and IL-6) correlates with a decreased production of specific antibodies (Fig. 2 and Fig. 3). The lower specific antibody synthesis observed in males may, therefore, be a consequence of a lower Th2 cytokine expression.

As mentioned earlier, $\mathrm{FB}_{1}$ is a potent inhibitor of ceramide synthase, an enzyme critical to sphingolipid biosynthesis. The sex-related effect of $\mathrm{FB}_{1}$ could be due to a sex-related difference in sphingolipid metabolism. A higher accumulation of free sphingoid bases was observed in the liver of female mice treated with $\mathrm{FB}_{1}$ when compared with males (Bhandari et al. 2001). In pigs, however, after consumption of diet contaminated with $10 \mathrm{mg} \mathrm{FB} / \mathrm{kg}$, the increase in free sphingoid bases in the lung was more pronounced in males than in females (Rotter et al. 1996). Sphingosine is a potent competitive inhibitor of protein kinase C (Gopee \& Sharma, 2003) and, recently, it has been shown that protein kinases are involved in the regulation of cytokine synthesis. In human macrophages, for example, inhibition of protein kinase $\mathrm{C} \zeta$ selectively suppressed IL-10 production (Foey \& Brennan, 2002). Thus, the higher inhibition of IL-10 expression observed in male pigs upon $\mathrm{FB}_{1}$ exposure (Fig. 3) may be due to a higher increase of sphingosine and a greater suppression of protein kinase $\mathrm{C}$.

The species-specific effect of $\mathrm{FB}_{1}$ on sphingolipid metabolism may also explain the contrasting effects on cytokine synthesis observed in mice and pigs. Free sphingoid bases inhibit lymphocyte growth, especially the Th2 subtype
(Tokura et al. 1996; Desai et al. 2002). Exposure to $\mathrm{FB}_{1}$ increases free sphingoid bases in male pigs and in female mice (Rotter et al. 1996; Bhandari et al. 2001). By selectively acting on Th2 lymphocytes, these sphingoid bases could decrease synthesis of cytokines (IL-4, IL-6 and IL-10) in a sex- and species-dependent manner. Through its effect on sphingolipid metabolism, $\mathrm{FB}_{1}$ may also modulate the concentration of the different subclass of gangliosides, known to regulate cytokine production. GD1b, GT1b and GQ1b, for example, enhanced IL- 2 and IFN- $\gamma$ production but suppressed IL-4 and IL-5, IL-6 and IL-10 synthesis. GD1a and GM3, however, stimulate IL-10 production (Kanda, 1999; Kanda $\&$ Watanabe, 2000, 2001). Further studies are needed to determine the implication of species and sex on lipid metabolism and its modulation by $\mathrm{FB}_{1}$ on the observed variation of cytokine expression.

In conclusion, it has been shown that fumonisin has toxic effects on the immune response and that these effects are more pronounced in males that in females. Due to the possible risk and implications for pig production and human health, this sex specificity requires further investigation, especially in the areas highly contaminated with Fusarium species.

\section{Acknowledgements}

D. E. M. was supported by a doctoral fellowship from a bilateral project 'Réseau Formation-Recherche' between INRA, France and IBNA, Romania, granted by the 'Ministère de l'Éducation Nationale' and the 'Ministère de la Recherche' 
(Paris, France). I. T. was the recipient of an INRA post-doctoral fellowship. Thanks are also due to Dr Grossu, General Manager of IBNA, for her constant support and to $\mathrm{Dr}$ Trevor Smith for his editorial assistance.

\section{References}

Abbas AK, Murphy KM \& Sher A (1996) Functional diversity of helper T lymphocytes. Nature 383, 787-793.

Bhandari N, Brown CC \& Sharma RP (2002) Fumonisin $B_{1}$-induced localized activation of cytokine network in mouse liver. Food Chem Toxicol 40, 1483-1490.

Bhandari N, He Q \& Sharma RP (2001) Gender-related differences in subacute fumonisin $\mathrm{B}_{1}$ hepatotoxicity in BALB/c mice. Toxicology 165, 195-204.

Bolger M, Coker RD, Dinovi M, Gaylor D, Gelderblom MO, Paster N, Riley RT, Shephard G \& Speijers JA (2001) Fumonisins. In Safety Evaluation of Certain Mycotoxins in Food, Food and Agriculture Organization of the United Nations, paper no. 74. World Health Organization Food Additives, series 47, pp. 103-279. Geneva: WHO FOOD Additives.

Bondy G, Suzuki C, Barker M, Armstrong C, Fernie S, Hierlihy L, Rowsell P \& Mueller R (1995) Toxicity of fumonisin B ${ }_{1}$ administered intraperitoneally to male Sprague-Dawley rats. Food Chem Toxicol 33, 653-665.

Bouhet S, Hourcade E, Loiseau N, Fikri A, Martinez S, Roselli M, Galtier P, Mengheri E \& Oswald IP (2004) The mycotoxin, fumonisin $\mathrm{B}_{1}$ alters the proliferation and the barrier function of porcine intestinal epithelial cells. Toxicol Sci 77, 165-171.

Bouhet S \& Oswald IP (2005) Effects of mycotoxins, fungal food contaminants, on the intestinal epithelial cell derived innate immune response. Vet Immunol Immunopathol 108, 199-209.

Darwich L, Pie S, Rovira A, Segales J, Domingo M, Oswald IP \& Mateu E (2003) Cytokine mRNA expression profiles in lymphoid tissues of pigs naturally affected by postweaning multisystemic wasting syndrome. J Gen Virol 84, 2117-2125.

Desai et al. (2002). Fumonisins and fumonisin analogs as inhibitors of ceramide synthase and inducers of apoptosis. Biochim Biophys Acta 1585, 188-192

Diehl S \& Rincon M (2002) The two faces of IL-6 on Th1/Th2 differentiation. Mol Immunol 39, 531-536.

Dozois CM, Oswald E, Gautier N, Serthelon JP, Fairbrother JM \& Oswald IP (1997) A reverse transcription-polymerase chain reaction method to analyse porcine cytokine gene expression. Vet Immunol Immunopathol 58, 287-300.

Fink-Gremmels J (1999) Mycotoxins: their implications for human and animal health. Vet $Q$ 21, 115-120.

Foey \& Brennan (2002) Conventional protein kinase C and atypical protein kinase Czeta differentially regulate macrophage production of tumour necrosis factor-alpha and interleukin-10. Immunology 112, 44-53.

Fournout S, Dozois CM, Odin M, et al. (2000) Lack of a role of cytotoxic necrotizing factor 1 toxin from Escherichia coli in bacterial pathogenicity and host cytokine response in infected germfree piglets. Infect Immun 68, 839-847.

Gopee NV \& Sharma RP (2003) Sphingoid bases and their phosphates: transient activation and delayed repression of protein kinase $\mathrm{C}$ isoforms and their possible involvement in fumonisin $\mathrm{B}_{1}$ cytotoxicity. Toxicology 187, 239-250.

Halloy DJ, Gustin PG, Bouhet S \& Oswald IP (2005) Oral exposure to culture material extract containing fumonisins predisposes swine to the development of pneumonitis caused by Pasteurella multocida. Toxicology 213, 34-44.

Haschek WM, Gumprecht LA, Smith G, Tumbleson ME \& Constable PD (2001) Fumonisin toxicosis in swine: an overview of porcine pulmonary edema and current perspectives. Environ Health Perspect 109, 251-257.

He Q, Bhandari N \& Sharma RP (2002) Fumonisin $B_{1}$ alters sphingolipid metabolism and tumor necrosis factor alpha expression in heart and lung of mice. Life Sci 71, 2015-2023.

Howard PC, Eppley RM, Stack ME, Warbritton A, Voss KA, Lorentzen RJ, Kovach RM \& Bucci TJ (2001) Fumonisin B1 carcinogenity in a two-year feeding study using F344 rats and B6C3F1 mice. Environ Health Perspect 2, 277-282.

International Agency for Research on Cancer (2002) Some traditional herbal medicines, some mycotoxins, naphthalene and styrene. In IARC Monographs on the Evaluation of Carcinogenic Risks to Humans, 82, 275-366, Lyon, France: IARC Press.

International Programme on Chemical Safety (2000) Fumonisin $B_{1}$. In Environmental Health Criteria, no. 219, pp. 43-50. Geneva: WHO.

Johnson VJ \& Sharma RP (2001) Gender-dependent immunosuppression following subacute exposure to fumonisin $\mathrm{B}_{1}$. Int Immunopharmacol 11, 2023-2034.

Kanda N (1999) Gangliosides GD1a and GM3 induce interleukin-10 production by human T cells. Biochem Biophys Res Commun 256, $41-44$.

Kanda N \& Watanabe S (2000) Ganglioside GD1a enhances immunoglobulin production by human blood mononuclear cells. Exp Hematol 28, 672-679.

Kanda N \& Watanabe S (2001) Gangliosides GD1b, GT1b, and GQ1b enhance IL-2 and IFN-gamma production and suppress IL-4 and IL-5 production in phytohemagglutinin-stimulated human T cells. J Immunol 166, 72-80.

Li YC, Ledoux DR, Bermudez AJ, Fritsche KL \& Rottinghaus GE (2000) The individual and combined effects of fumonisin $B_{1}$ and moniliformin on performance and selected immune parameters in turkey poults. Poult Sci 79, 871-878.

Marin DE, Taranu I, Bunaciu RP, Pascale F, Tudor DS, Avram N, Sarca M, Cureu I, Criste RD, Suta V \& Oswald IP (2002) Changes in performance, blood parameters, humoral and cellular immune responses in weanling piglets exposed to low doses of aflatoxin. J Anim Sci 80, 1250-1257.

Martinova EA \& Merrill AH Jr (1995) Fumonisin $B_{1}$ alters sphingolipid metabolism and immune function in $\mathrm{BALB} / \mathrm{c}$ mice: immunological responses to fumonisin $\mathrm{B}_{1}$. Mycopathologia 130, $163-170$

Merrill AH Jr, Sullards MC, Wang E, Voss KA \& Riley RT (2001) Sphingolipid metabolism: roles in signal transduction and disruption by fumonisins. Environ Health Perspect 109, 283-289.

Mocellin S, Panelli MC, Wang E, Nagorsen D \& Marincola FM (2003) The dual role of IL-10. Trends Immunol 24, 36-43.

Murphy PA, Hendrich S, Hopmans EC, Hauck CC, Lu Z, Buseman G $\&$ Munkvold G (1996) Effect of processing on fumonisin content of corn. Adv Exp Med Biol 392, 323-334.

Murphy PA, Rice LG \& Ross PF (1993) Fumonisin $B_{1}, B_{2}$ and $B_{3}$ content of Iowa, Wisconsin and Illinois corn and corn screening. J Agric Food Chem 41, 263-266.

Nelms K, Huang H, Ryan J, Keegan A \& Paul WE (1998) Interleukin-4 receptor signalling mechanisms and their biological significance. Adv Exp Med Biol 452, 37-43.

Oswald IP, Desautels C, Laffitte J, Fournout S, Peres SY, Odin M, Le Bars P, Le Bars J \& Fairbrother JM (2003) Mycotoxin fumonisin $\mathrm{B}_{1}$ increases intestinal colonization by pathogenic Escherichia coli in pigs. Appl Environ Microbiol 69, 5870-5874.

Oswald IP, Marin DE, Bouhet S, Pinton P, Taranu I \& Accensi F (2005) Immunotoxicological risk of mycotoxins for domestic animals. Food Addit Contam 22, 354-360.

Pié S, Lalles JP, Blazy F, Laffitte J, Sève B \& Oswald IP (2004) Weaning is associated with an upregulation of expression of inflammatory cytokines in the intestine of piglets. J Nutr 134, $641-647$. 
Qureshi MA, Garlich JD, Hagler WM Jr \& Weinstock D (1995) Fusarium proliferatum culture material alters several production and immune performance parameters in White Leghorn chickens. Immunopharmacol Immunotoxicol 17, 791-804.

Riley RT, Voss KA, Norred WP, Sharma RP, Wang E \& Merrill AH (1998) Fumonisins: mechanism of mycotoxicity. Rev Med Vet 149, 617-626.

Rotter BA, Thompson BK, Prelusky DB, Trenholm HL, Stewart B, Miller JD \& Savard ME (1996) Response of growing swine to dietary exposure to pure fumonisin $\mathrm{B}_{1}$ during an eight-week period: growth and clinical parameters. Nat Toxins 4, 42-50.

Scudamore KA, Nawaz S \& Hetmanski MT (1990) Mycotoxins ingredients of animal feeding stuffs: II. Determination of mycotoxins in maize and maize products. Food Addit Contam 15, $30-55$.

Taranu I, Marin DE, Bouhet S, Pascale F, Bailly JD, Miller JD, Pinton P \& Oswald IP (2005) Mycotoxin fumonisin $B_{1}$ alters the cytokine profile and decreases vaccinal antibody titer in pigs. Toxicol Sci 84, 301-307.
Tokura Y, Wakita H, Yagi H, Nishimura K, Furukawa F \& Takigawa M (1996) Th2 suppressor cells are more susceptible to sphingosine than Th1 cells in murine contact photosensitivity. $J$ Invest Dermatol 107, 34-40.

Tornyos G, Kovacs M, Rusvai M, Horn P, Fodor J \& Kovacs F (2003) Effect of dietary fumonisin B1 on certain immune parameters of weaned pigs. Acta Vet Hung 51, 171-179.

Tran ST, Bailly JD, Tardieu D, Durand S, Benard G \& Guerre P (2003) Sphinganine to sphingosine ratio and predictive biochemical markers of fumonisin B1 exposure in ducks. Chem Biol Interact 146, 61-72. Tryphonas H, Bondy G, Miller JD, Lacroix F, Hodgen M, Mcguire P, Fernie S, Miller D \& Hayward S (1997) Effects of fumonisin $B_{1}$ on the immune system of Sprague-Dawley rats following a 14-day oral (gavage) exposure. Fundam Appl Toxicol 39, 53-59.

Zomborszky MK, Vetesi F, Repa I, Kovacs F, Bata A, Horn P, Toth A \& Romvari R (2000) Experiment to determine limits of tolerance for fumonisin $\mathrm{B}_{1}$ in weaned piglets. $J$ Vet Med 47, 277-286.

Zomborszky-Kovacs M, Vetesi F, Horn P, Repa I \& Kovacs F (2002) Effects of prolonged exposure to low-dose fumonisin $\mathrm{B}_{1}$ in pigs. $J$ Vet Med 49, 197-201. 